\title{
Association between Meckel's diverticulum and Crohn's disease: a retrospective review
}

\author{
H J N Andreyev, R A Owen, I Thompson, A Forbes
}

\begin{abstract}
The operation notes and pathology records of 294 consecutive patients who had right hemicolectomy for Crohn's disease were reviewed. A Meckel's diverticulum was found in $\mathbf{1 7}$ (5.8\%) of these patients, $2-3$ times the expected rate in the general population. At least $50 \%$ of diverticula in the normal population contain heterotopic mucosa, but none was found in those diverticula that were examined from this group. The increased prevalence of Meckel's diverticulum in patients with Crohn's disease confirms previous anecdotal reports, but the cause for the increased frequency remains unexplained. The significance of this finding is discussed.
\end{abstract}

(Gut 1994; 35: 788-790)

There have been suggestions that Meckel's diverticulum is found more commonly in patients diagnosed as having terminal ileal Crohn's disease than in the general population. ${ }^{1}$ It is not understood why this might be. We have recently described a patient who was thought to have Crohn's disease, but at laparotomy, a Meckel's diverticulum was found at the point where the extensive terminal ileal ulceration began. The histological findings in this case were more consistent with chronic inflammation caused by acid secretion from heterotopic gastric epithelium within the diverticulum than with Crohn's disease (unpublished data).

The question then arose as to whether there was a real increase in the incidence of Meckel's diverticulum in patients considered to have Crohn's disease or whether this association could, in some cases, be accounted for by acid secretion from the diverticula giving rise to peptic ulceration mimicking Crohn's disease.

\section{Methods}

A register is kept at St Mark's Hospital of patients who have had resections for Crohn's disease. All patients whose first resection, of any type, for Crohn's disease was a right hemicolectomy performed at St Mark's, were identified. The prevalence of Meckel's diverticulum was obtained from a summary of their past history, the surgeon's operation notes, and the pathology report on the resected specimen. The pathology slides from those patients who had a Meckel's diverticulum were reviewed by two experienced gastrointestinal pathologists. If the diverticulum had been resected and sectioned, it was examined for evidence of heterotopic epithelium. The histology of the resected small bowel and colon of these patients was also reviewed to see if histo- logical features of typical Crohn's disease were present or if chronic inflammation from acid secretion could account for the changes.

\section{Results}

Between 1947 and 1992, 294 St Mark's Hospital patients had right hemicolectomy as their first resection for Crohn's disease. The operation sheets of 291 patients were available. Pathology records were available for all patients. Seventeen patients from this group had a reported Meckel's diverticulum $(5 \cdot 8 \%)$ and the terminal ileal inflammation started close to the mouth of the diverticulum in at least four patients. Ten were women and seven, men. Their age at resection ranged from 18-56 years (median 32 years old).

MISSING RECORDS

Three patients' operation records are missing; none had evidence of Meckel's diverticulum according to pathology reports and all had histology typical of Crohn's disease with granulomata. One patient had no problems postoperatively, a second patient subsequently relapsed and has a Meckel's diverticulum at the site of the recurrence on a postoperative barium follow through (he has not been included as one of the 17 Meckel's positive patients). He has had a Meckel's scan, which shows no evidence of heterotopic mucosa. Nothing further is known about the third patient.

\section{CLINICAL DETAILS}

The time to surgery from the onset of symptoms in these patients varied from six months to 10 years (median four years). Postoperatively, seven patients have remained well for a period of between six months and 18 years (median 10 years), two patients have had further surgery, and five have intermittent symptoms that have not required substantial intervention. Follow up details on three patients are not available. No Meckel's diverticulum was seen by the pathologist that had not been previously reported by the surgeon.

\section{MECKEL'S DIVERTICULA UNAVAILABLE FOR} HISTOLOGICAL EXAMINATION

Three patients had resection of a Meckel's abscess elsewhere before they were referred to St Mark's. It is not known whether these diverticula contained heterotopic mucosa. One meckelectomy was performed one year before a diagnosis of Crohn's disease was made. A second Meckel's abscess was resected after a wood splinter in a can of spaghetti hoops lodged in the diverticulum.
Whipps Cross Hospital, London

Correspondence to:

Dr A Forbes, St Mark's ECIV 2PS.

Accepted for publication 20 October 1993 
The patient received compensation from the food manufacturer but after resection of the abscess, abdominal symptoms persisted and Crohn's disease was diagnosed four years later. The third patient had a Meckel's abscess complicated by fistulation, removed two years before Crohn's disease became symptomatic. All three patients, at subsequent right hemicolectomy had typical histological changes of Crohn's disease with granulomata. Postoperatively, two have remained well while one has developed the typical course of severe relapsing disease.

In three patients, the Meckel's diverticulum was left in situ. One is reported as being wide necked, a second as being very small, the dimensions of the third are not commented upon, and at a subsequent laparotomy it is not mentioned in the operation notes. All three patients had histologically typical Crohn's disease with granulomata, in two patients affecting the bowel wall and in one, the lymph nodes.

\section{MECKEL'S DIVERTICULA RESECTED}

Of the remaining 11 patients who had a Meckel's diverticulum resected, only seven diverticula were examined histologically by the original pathologist. None of these contained heterotopic mucosa. These patients had typical transmural small bowel Crohn's disease, although granulomata were seen in only two. One of these patients (with no evidence of gastric mucosa in his diverticulum), some years preoperatively had a positive Meckel's scan, which must therefore be presumed to be a false positive unless the extensive heterotopia required to give a positive scan can disappear.

Of the four cases with Meckel's diverticula that were not analysed histologically, three had typical transmural Crohn's disease, two with granulomata, one without. The fourth patient did not have typical histology for Crohn's disease. The disease was not transmural and there were no granulomata. The colectomy specimen, however, showed evidence of an indeterminate colitis with the proximal end of the resected specimen normal and the distal end showing inflammation. It is therefore very unlikely that secretion from the diverticulum could have caused the histological changes.

\section{DISCUSSION}

Meckel's diverticulum is found in between 0.6 and $3 \%$ of the normal population. ${ }^{2}$ This review shows that the prevalence of Meckel's diverticula is increased up to three times above normal in patients with Crohn's disease and supports previous anecdotal evidence. It is possible that this incidence is an underestimate (if surgeons and pathologists fail to record their findings) and most unlikely that Meckel's diverticulum is overreported.

It is not always easy to be certain of a diagnosis of Crohn's disease and there are often no infallible histological markers to ensure an absolutely secure diagnosis. The proposition that some patients diagnosed as having Crohn's disease might in fact have had a terminal ileitis due to chronic acid secretion was therefore, a tempting one. It is possible that unless a pathologist was invited to make this diagnosis it might well be missed especially if the clinical impression was of Crohn's disease. In our patients with Meckel's diverticula, nearly all had typical Crohn's disease, and where the histology was not quite typical, the histological changes seen were not consistent with those induced by peptic inflammation.

In the general population, about $50 \%$ of Meckel's diverticula contain heterotopic mucosa and of these perhaps as many as $65 \%$ contain gastric mucosa. ${ }^{3-6}$ Anecdotal reports ${ }^{78}$ have pointed to acid secretion from gastric mucosa within a Meckel's diverticulum as a rare cause of terminal ileal inflammation but it remains possible that patients with acid induced inflammation generally have mild symptoms and do not come often to surgery. A report, however, of five Meckel's diverticula resected from 27 patients with terminal ileitis (incidence $18.5 \%$ ) found that none of the diverticula contained heterotopic mucosa ${ }^{9}$ and our study, while confirming an increased prevalence of Meckel's diverticula has also found a similar surprising absence of heterotopic mucosa. Therefore, prospective evaluation of patients presenting with terminal ileal Crohn's disease with technetium scanning is not warranted, particularly as patients with inflammatory bowel disease often have false positive scans.

Our findings may have occurred by chance but at least three other explanations for this association exist. Firstly, Meckel's diverticulum and Crohn's disease may occur in the same susceptible subjects because of a common underlying factor. Secondly, Crohn's disease may exist for many years before it becomes clinically apparent although it seems unlikely that preclinical Crohn's disease can act at or before three months of gestation (when the vitelline duct is normally eradicated) to promote retention of the diverticulum. The third and most exciting possibility is that in some way the presence of a Meckel's diverticulum predisposes to Crohn's disease.

A Meckel's diverticulum might be considered to constitute a 'blind loop', which harbours infective agents or inflammatory antigens and is an area of increased gastrointestinal permeability. This would fit with data that suggest that increased permeability is one of the earliest signs and even the cause of relapse in Crohn's disease and a marker of increased familial risk. Alternatively, it is possible that a Meckel's diverticulum provides a fulcrum for mechanical disturbances of bowel motility or promotes ischaemia (for example, by intussusception) or may be associated with aberrant lymphatic drainage. Any or all these possibilities may predispose the patient to Crohn's disease.

This study confirms anecdotal reports over many years that Meckel's diverticulum is more common in patients with Crohn's disease than in the general population but suggests that our hypothesis to explain this finding, that acid secretion from gastric mucosa within the diverticulum causes this terminal ileitis, is not correct in most patients.

1 Bondeson L, Starck-Bondeson AG. Crohn's disease in heterotopic gastric mucosa in a Meckel's diverticulum. Acta Pathol Microbiol Scand 1974; 82 (A): 427-30. 
2 Soltero MJ, Bill AH. The natural history of Meckel's diverticulum and its relation to incidental removal: a study of 202 cases of diseased Meckel's diverticula found in King County Washington over a fifteen year period. Am F Surg 1976; 132: 168-73.

3 Baker AL, Marshall SF. Meckel's diverticulum: a report on ninety three cases. Am Surg 1955; 21 : 1173-81.

4 Aubrey DA. Meckel's diverticulum: a review of 66 emergency Meckel diverticulectomies. Arch Surg 1970; 100: ency 144 .

5 Yamaguchi M, Takeuchi S, Awazu S. Meckel's diverticulum: investigation of 600 patients in the Japanese literature. $A m \mathcal{F}$ investigation of 600 patients in the Japanese literature. $A m \mathcal{F}$

6 MacKay WC, Dineen P. A fifty year experience with Meckel's diverticulum. Surg Gynecol Obstet 1983; 156: 56-64. 7 Rau P, O'Brien M, Ezpeleta M, Williams L, Kramer P, Burakoff $R$. Bleeding Meckel's diverticulum in a patien with inflammatory bowel disease. 7 Clin Gastroenterol 1982; 4: 455-9.

8 Traube M, Iswara K, Reddy RS. Meckel's diverticulum: an unusual case with ileal stricture. Am f Gastroenterol 1981; 76 : 291-6.

9 Ekman CN. Regional enteritis associated with Meckel's diverticulum: a report of five cases. Gastroenterology 1958; 34: $130-4$.

10 Wyat $\mathrm{J}$, Vogelsang H, Hubl W, Waldoer T, Lochs H Intestinal permeability and the prediction of relapse in Crohn's disease. Lancet 1993; 341: 1437-9. 